\title{
Evaluation of Hoffer $Q$ formula in Short and long axial lengths
}

\author{
Ahmed I Galhoom, MD; Mostafa M Mostafa, \\ MD;Mohamed I Elkasaby,MD; and Ali A Ghali MD. \\ Department of ophthalmology, Faculty of medicine Al Azhar University.
}

\begin{abstract}
Purpose: Evaluation of The accuracy of Hoffer Q formula for intraocular lens (IOL) power calculation in short and long axial lengths of the eye.
\end{abstract}

Methods: 100 eyes divided equally into 2 groups: group I (50 eyes) with axial length more than 24.5 and group II( 50 eyes) with axial length more less than 22. Comparison between both groups was done as regards post operative residual refractive error after IOL implantation using Hoffer Q formula.

Results: Insignificant difference between the 2 groups as regard post operative residual refractive error. In short length eyes, the mean postoperative refractive error with Hoffer Q formula was $0.80 \pm 0.33 \mathrm{D}$. In long eyes, the mean postoperative refractive error was 1.23 $\pm 0.70 \mathrm{D}$. The results show that the best performing formula was in short eyes $(\mathrm{P}=0.012)$.

Conclusion: Insignificant difference as regards postoperative residual refractive error between both groups but Hoffer Q formula best performed in short eyes.

\section{Introduction:}

Today, cataract surgery with intraocular lens IOL implantation is a successful procedure. It is minimally invasive, rehabilitation is quick, and the complication rate is low. In addition, the refractive outcome is excellent and vision can be improved to a level better than before cataract formation .12

There is increasing evidence of the value of preoperative biometry to calculate the power of an intraocular implant used during cataract surgery to avoid the large range of postoperative refractive error associated with use of a standard power lens .4

Postoperative refractive errors after intraocular lens implantation can be a result of different reasons. The most likely is incorrect IOL calculation due to incorrect measurements of the

eye .10

\section{(A) Theoretical IOL formulas}

Theoretical formulas represented a significant advance over other methods of estimating implant power, but a formula based on theoretical optics cannot take into account the complex function of the eye. Moreover, the values required for the formula are derived through A- scan and keratometry measurements, and these devices are not precise enough to ensure the reliable data being used in the formulas. Thus theoretical formulas help the surgeon to anticipate what should result, not what will result from implantation. 15

Although in practice the theoretical formulas are generally reliable for eyes with axial lengths between 22 and $24.5 \mathrm{~mm}$, they tend to predict too large an emmetropic value in short eyes and too small value in long eyes. 


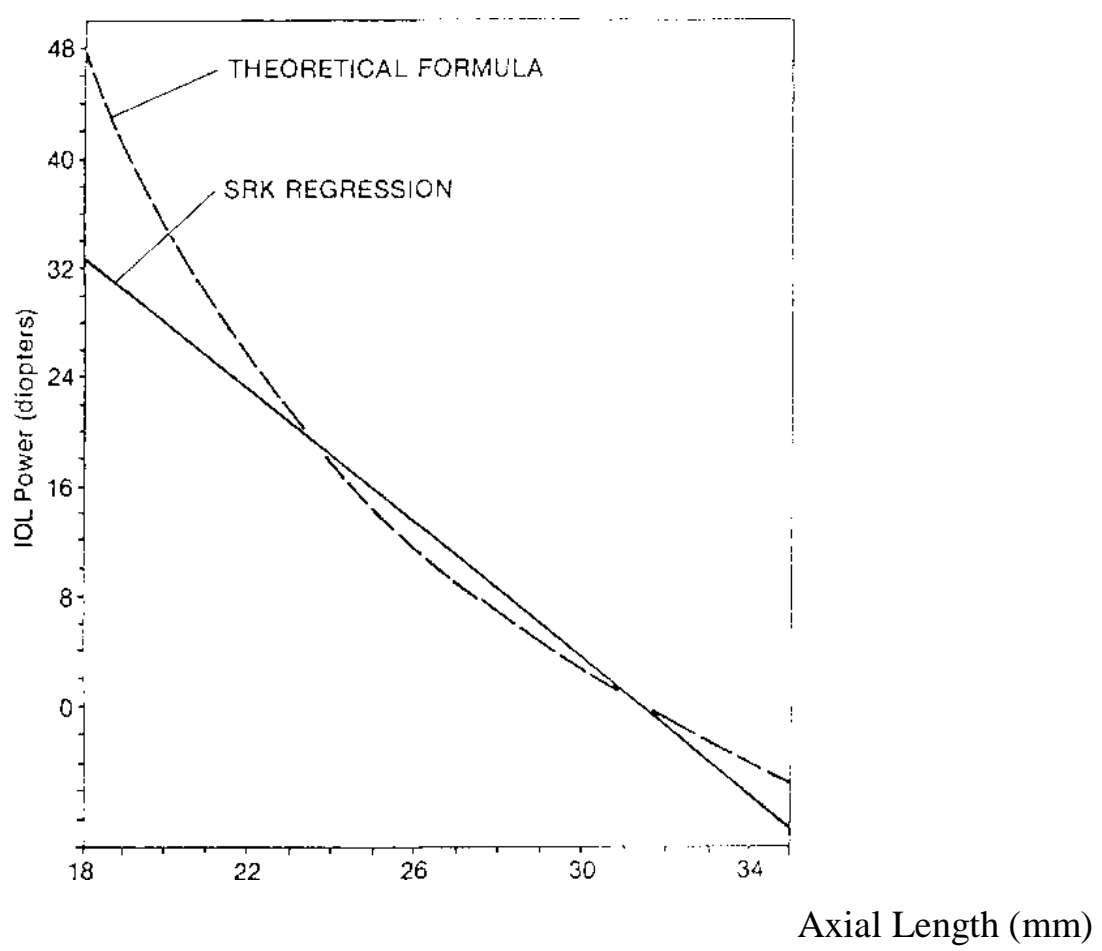

Fig. 1: Theoretical compared with regression determination of predicted IOL power..(Christopher et al.2000).

In addition, the complexity of the theoretical formulas makes them difficult to apply without the assistance of a calculator or a computer. Finally, the theoretical expressions still require a guess about the anterior chamber depth, and the ultimate result depends on the accuracy of that guess. As a result, there has been a tendency toward the simpler empirical formulas in clinical practice .1

Also, the problem in the theoretical formula is in the axial length measurement. The reason why it is difficult to measure the axial length accurately is that one must know the exact velocities of the ultrasound as it travels through the various structures of the eye. Because of the variation of the acoustic density of a cataract, these velocities cannot be known exactly. As a result, when cataractous lenses are much more acoustically dense than the average lens, the sound wave will move more rapidly through the lens and return to the transducer much more quickly than would have been expected for a given axial length. As a result of the velocity error, the eyes appear to be shorter. The formula consequently calculates an IOL power for an axial length which is too short. The patient then becomes over minus (too myopic). Theoretical formulae help the surgeon to anticipate what should result, not what will result from implantation .16

\section{(1)1st Generation formulas}

In 1967, Fyodorov presented his theoretical formula based on geometric optics utilizing keratometry and A-scan ultrasonography ${ }^{9}$ Colenbrander, Thijssen, Vander Heijde and Binkhorst had also published theoretical formulae $^{9}$

\section{(2)Second Generation Theoretical Formulas}

When these original theoretical formulas were developed, all successful implants used were iris-supported lenses. When both anterior and posterior chamber implants became available, new estimations had to be made for the distance from the cornea to the implant (postoperative anterior chamber 
depth) moreover there is greater variability in the position of a posterior chamber lens than with an iris supported lens.9

All second generation theoretical formulas, by definition, predict postoperative anterior chamber depth (ACD), i.e. provide an estimate of the expected postoperative IOL position in each individual eye. This predicted pseudophakic ACD is then entered into the physiological optical formula.13

The Hoffer Q formula was developed to predict the pseudophakic anterior chamber depth (ACD) for theoretic IOL power formulas. It relies on a personalized ACD, axial length, and corneal curvature. In 180 eyes, Hoffer Q formula proved more accurate than those using a constant ACD $(p<0.0001)$ and equal $(p=0.63)$ to those using the actual postoperative measured ACD (which is not possible clinically). 6

A retrospective analysis of 76 eyes of 56 patients underwent cataract surgery with IOLs ranging in power from 30 to 35 diopters. Differences between the predicted and actual postoperative refraction were analysed for each different formula, the results showed the mean refractive error in Hoffer Q (-0.70 +/- 0.14 D).11

\section{Material and Methods:}

The study includes (100) eyes with age ranging from 40 to 80 years (with average age $58.49 \pm 8.29$ years).

The patients were divided into the following two groups:

Group I (50 eyes): included eyes with long axial length (more than 24.5).

Group II (50 eyes): included eyes with short axial length (less than 22).

Each group undergone calculation of IOL using the Hoffer Q formula.

All cases were done in Al Azhar university hospitals.

Preoperative preparation: Included examination of visual acuity, applanation tonometry, slit lamp biomicroscopy to evaluate the cornea, iris and lens, Fundus examination and refraction were done whenever possible. Keratometry to measure the diopteric power of the cornea in the two main principal meridians using a keratometer and an average keratometric reading was taken, Ultrasonography was performed to exclude the complicated cases in suspected posterior segment disease and to measure the axial length along the visual axis. They were prepared for biometry by instillation of 1 to 2 drops of tropicamide $1 \%$ (This produces mild dilatation of the pupil and facilitates the detection of echo spikes of anterior and posterior lens capsules).

The axial lengths were measured along the visual axis with Alcon A/B UltraScan Digital B and Mentor Advent A/B Ultrasound. They are microprocessorbased, digital instruments that use pulsed ultrasound to determine the intraocular distances, axial length, lens thickness and anterior chamber depth.

\section{Biometry:}

After instillation of 1 to 2 drops of benoxinate hydrochloride $0.4 \%$ into the conjunctival sac, the patient was properly positioned and the probe carefully placed on the cornea. The probe should be perpendicular to the cornea along the visual axis of the eye aided by fixation light of the transducer and indentation of the cornea to avoid underestimation of the axial length. Good applanation technique and proper alignment should result in good scan with sharp high spikes.

The average axial length of each eye, average keratometric reading, and a specific A-constant for each lens type were used for calculation, the power of an intraocular lens resulting in a desired postoperative refraction using Hoffer Q formulae.In all cases postoperative emmetropia was aimed.

All patients were subjected to phacoemulsification with implantation of posterior chamber IOL. The operations were done under general or local anesthesia in the period from January 2008 to December 2008.

the patients were followed up postoperatively for 6 months, regarding visual acuity, refraction, condition of the 
cornea, applanation tonometry and fundus examination,.

At the end of 6 months, postoperative refraction was measured by retinoscopy, and autorefractometer. The spherical equivalent was used for comparison of the results.

\section{Results}

Table (1) Residual error in eyes using Hoffer Qformula

\begin{tabular}{|c|c|c|}
\hline Range (D) & No. of eyes & Percentage of total \\
\hline$<\mathbf{1}$ & 50 & $50 \%$ \\
\hline $\mathbf{1 - 2}$ & 48 & $48 \%$ \\
\hline $\mathbf{2 . 2 5 - 3}$ & 2 & $2 \%$ \\
\hline Total & 100 & $100 \%$ \\
\hline
\end{tabular}

The mean absolute error was $0.94( \pm 0.52) \mathrm{D}$ regardless of whether the error was to the myopic or hyperopic side.

Fig (2)Postoperative residual error in Hoffer Qformula

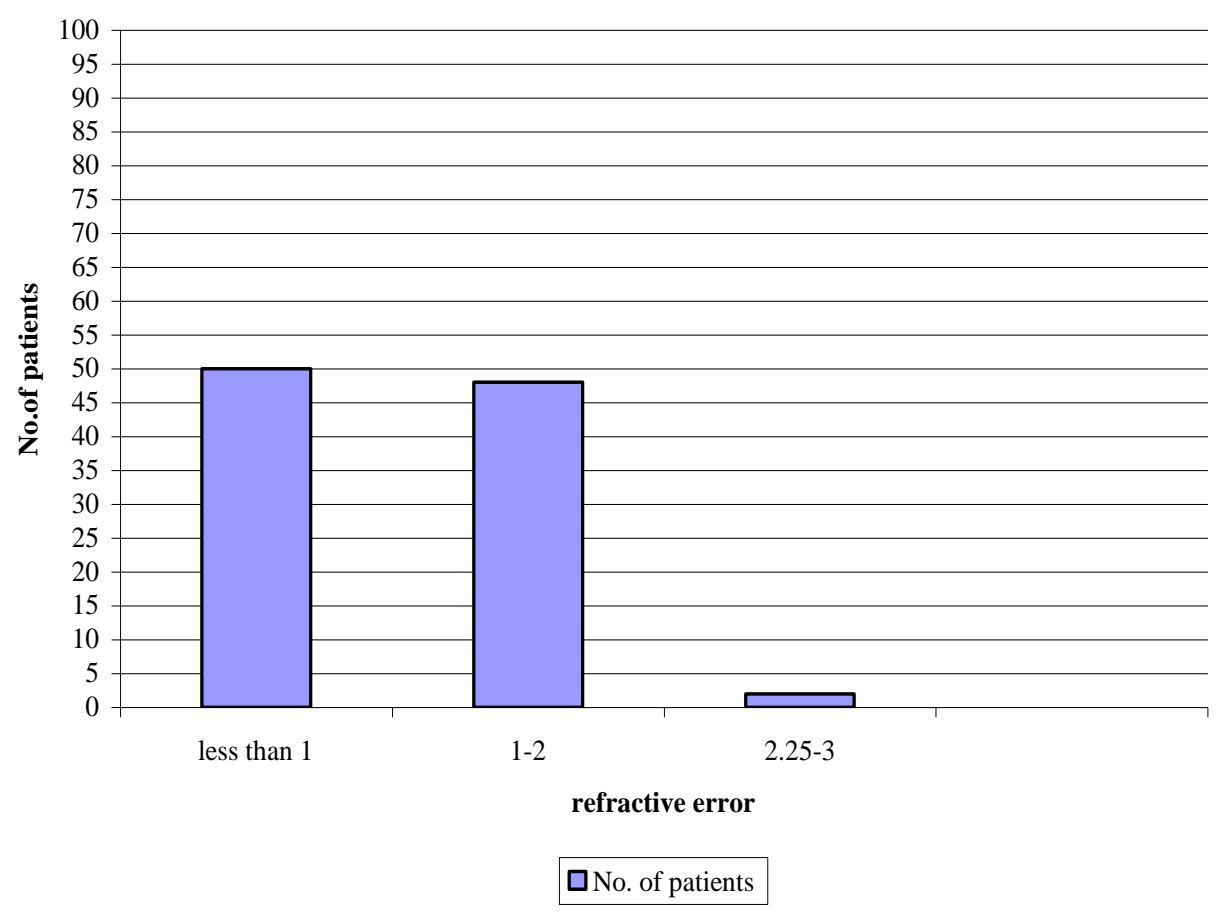


Table (2) Mean absolute residual error in relation to axial length.

\begin{tabular}{|c|c|c|}
\hline axial length group & $\begin{array}{c}\text { Mean } \\
\text { absolute }\end{array}$ & \\
\hline short axial length group & 0.80 & \pm 0.33 \\
\hline long axial length group & 1.23 & \pm 0.70 \\
\hline
\end{tabular}

The table shows that the mean absolute error (regardless of whether the error was to the myopic or hyperopic side) was $1.01 \mathrm{D} \pm 0.51$ and $\mathrm{P}$ value $=0.012$. The short axial length had the least mean residual error.

\section{Discussion}

IOL power calculation using the Hoffer Q formula revealed within $2 \mathrm{D}$ of the expected postoperative refraction in $98 \%$ of 100 eyes and $100 \%$ were within 3D.

The mean absolute error in Hoffer Q in this study was $1.01 \pm 0.51 \mathrm{D}$.

In another studies $96.8 \%$ of 6 patients with 12 eyes were within $2 \mathrm{D}$ and all of them were within 3D of expected refraction 8 , and $2 \mathrm{D}$ or less of expected refraction in $94.43 \%$ of 75 eyes. 7

\section{Relation between Axial length and postoperative refraction:}

In short axial lengths, the mean postoperative refractive error with Hoffer Q formula was $0.80 \pm 0.33 \mathrm{D}$,

In long axial lengths, the mean postoperative refractive error with Hoffer Q was $1.23 \pm 0.70 \mathrm{D}$. The results show that the best performing formula was in short eyes $(\mathrm{P}=0.012)$.

Hoffer, studied the difference between theoretic and regression formulas, in 450 eyes. The Hoffer Q formula may be clinically more accurate than other formulas in eyes shorter than $22 \mathrm{~mm} .5$

Roberto et al.(2000),stated that in eyes with axial lengths equal to or longer than 27.0 $\mathrm{mm}$, current formulas, SRK/T, Hoffer Q, and Holladay have a tendency to over minus patients between -1.0 and $-4.0 \mathrm{D}$. The formulas appear to perform better for plus-power IOL implantation than for minus-power IOL implantation. The use of
B-scan Ultrasonography to locate posterior pole staphylomas which is present occasionally temporal to the optic disc in some patients may improve the accuracy of IOL calculations in eyes with extreme myopia.14

In a retrospective study including 50 patients with myopia longer than $27.0 \mathrm{~mm}$ (Power range -6.0 to $+5.0 \quad \mathrm{D}$ ), the performances of the SRK/T, Hoffer Q, Holladay formulas in predicting accuracy of an IOL power that would meet the target refraction of +/-1.00 D were compared. The formulas tended to suggest underpowered IOLs, more severe in eyes with axial lengths greater than $30.00 \mathrm{~mm}$. These eyes accounted for most of the minus-power IOLs implanted. Back calculations of axial lengths in patients with minus-power IOLs showed that, on average, emmetropia could have been predicted by choosing shorter axial lengths (up to $2.72 \mathrm{~mm}$ shorter) than those used in the original IOL power calculations. So, in eyes with axial lengths longer than or equal to $27.0 \mathrm{~mm}$, current lens calculation formulas have a tendency to over minus patients between -1.0 and $4.0 \mathrm{D}$. The formulas appear to perform better for plus-power IOL implantation than for minus-power IOL implantation. 18

Hoffer reported that a lower mean absolute error was found for the average length eyes (22.0 to $24.5 \mathrm{~mm}$ ) by the Holladay and Hoffer Q formulas $(0.42 \mathrm{D} \pm 0.48$ and $0.43 \mathrm{D} \pm 0.50)$ respectively. For short eyes (< $22.0 \mathrm{~mm}$ ), the Hoffer $\mathrm{Q}$ and Holladay 
formulas performed better $(0.71 \mathrm{D} \pm 0.40$ and $0.72 \mathrm{D} \pm 0.28) .7$

Donoso et al.,(2003) determined the predictability of IOL power calculation formulas according to the axial length. The error for eyes $<22 \mathrm{~mm}$ was not statistically significant for Hoffer Q formula. So Hoffer Q formula provided the best predictive results in short eyes than in long eyes $(>28$ $\mathrm{mm}) .2$

A study to determine the accuracy of the Hoffer Q, intraocular lens (IOL) power calculation formulas in high myopic and high hyperopic refractive lens exchange was done. Prediction error (predicted refraction - postoperative refraction) and mean absolute error were back-calculated for the Hoffer Q, the results showed that the Hoffer Q formula performed better in hyperopic than myopic eyes. 17

Patients with high myopia having phacoemulsification with implantation of an IOL were evaluated and calculations were performed before and after IOL implantation, Results indicate that the Hoffer Q showed a mean deviation of 1.15 $\mathrm{D}$, which indicate small deviation of postoperative refraction from target refraction. 12

In eyes of axial length below $22 \mathrm{~mm}$ biometry was performed and IOL power was calculated using Hoffer Q formula. Refractive outcome was measured which showed a mean prediction error of $0.61 \mathrm{D}$ (SD 0.80).3

\section{Conclusion:}

It could be concluded that there is insignificant difference as regards postoperative residual refractive error in short and long axial length eyes using Hoffer Q formula but Hoffer Q formula provides best degree of predictive accuracy for IOL power calculation in short eyes than long eyes.

\section{References:}

1. Christopher MT, Peter SH and Warren JB
(2000): Optics of intraocular lenses in: Principles and Practice of Ophthalmology, $2^{\text {nd }}$ edition, the W.B. Saumders Company, St. Louis: Baltimore, Philadelphia, Toronto, 387: 5376-5390.

2. Donoso R, Mura JJ, Lopez M and Papic A (2003): Emmetropization at cataract surgery. Looking for the best IOL power calculation formula according to the eye length. Arch Soc Oftalmol. Sep; 78(9):477-80.

3. Gavin and Hammond (2008): Intraocular lens power calculation in short eyes. Eye Jul 22(7):935-8.

4. Gregory PT, Esbester RM and Boase D (1989):Accuracy of routine intraocular lens power calculation in a district general hospital. Br. J. Ophthalmol. 73: 57.

5. Hoffer KJ (1993): A comparison of theortic and regression formulas. J Cataract Refract Surg Nov; (19):700-712.

6. Hoffer KJ (1994): Ultrasound velocities for axial eye length measurement. Journal of Cataract Refractive Surgery, 20 (5): 554-62.

7. Hoffer KJ (2000): Clinical results using the Holladay intraocular lens power formula.J Cataract Refract Surg Aug.; (26):1233-1237.

8. Inatomi M, Ishii K, and Koide RJ (1997): Intraocular lens power calculation for microphthalmos. J Cataract Refract Surg Oct; 23(8):1208-12.

9. Jaffe NS, Jaffe MS and Jaffe GF (1990): Intraocular lens implants in: Cataract surgery and its complications, fifth edition, C.V. Mosby Company,St.Louis:Baltimore,Philadelphia,Toro nto, 8:128-295.

10. Kohnen S (2000): Postoperative refractive error resulting from incorrectly labeled intraocular lens power. J Cataract Refract Surg May; 26(5):777-8.

11. Maclaren RE, Natkunarajah M ,Riaz Y, Bourne RR, Restori M and Allan BD.(2007): Biometry and formula accuracy with intraocular lenses used for cataract surgery in extreme hyperopia. Am J Ophthalmol. Jun; 143(6):920931.

12. Nemeth J, Fekete $\mathrm{O}$ and Pesztenlehrer N.(2003):Optical and ultrasound measurement of axial length and anterior chamber depth for intraocular lens power calculation. J. Cataract. Refract. Surg. Jan; 29(1):85-8.

13. Petermeier K, Gekeler F, and Messias A,Spiter MS, and Haigis W (2009): Intra lens power calculation and optimized constants for highly myopic eyes.J. Cataract. Refract. Surg., 35 (9): 1575-81.

14. Roberto Z, Mitchell C, Shultz $\mathrm{T}$ and Jonathan M (2000):Intraocular lens power calculations in patients with extreme myopia. $\mathbf{J}$ 
Cataract Refractive Surg., May Vol.26,668:674. 15. Sanders DR, Retzlaff J and Kraff MC (1988): Comparison of the SRK II formula and the other second generation formulae.J. Cataract Refract. Surg., 14 (3): 136.

16. Sunita A, Athiya A and Mahipal SS (2000):Biometry:In Phacoemulsification, laser cataract surgry and foldable IOLs , $2^{\text {nd }}$ edition, Jaypee brothers medicals publishers ltd, New Delhi,(1): 12-25.
17. Terzi E, Wang L and Kohnen (2009): Accuracy of modern intraocular lens power calculation formulas in refractive lens exchange for high myopia and high hyperopia.J. Cataract. Refract. Surg., 35 (7): 1181-9.

18. Zaldivar R, Shultz MC, Davidorf JM and Holladay JT (2000): Intraocular lens power calculations in patients with extreme myopia. J Cataract Refract Surg. May; 26(5):668-74. 
تقييم معادلة( هوفر كيو) فى حالتى الطول المحورى القصير والطول المحورى الطويل للعين

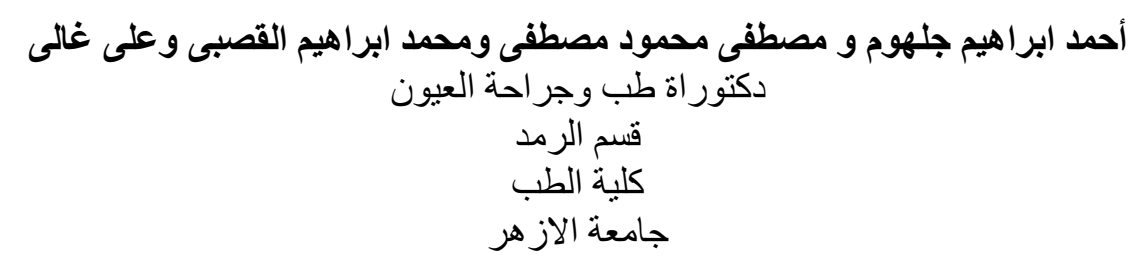

الغرض من البحث هو تقييم دقة معادلة هوفر كيو لقياس قوة العدسات التى تزرع داخل العين فى الطول المحورى القصير والطول المحورى الطويل للعين.

$$
\text { أجريت الاراسة على عدد مائة عين تم تقسيمهم الى مجموعتين : }
$$

المجموعة الاولى الثتملت على خمسين عين ذات طول محورى أكثر من 24.5مل و المجموعة الثانية خمسين عين ذات طول محورى أقل من 22 مل.

النتائج تقارن طبقا لقوة انكسار العين بعد عمليات المياه البيضاء وزرع العدسة باستخدام معادلة هوفر كيو لقياس قوة العدسة.

اظهرت النتائج ان معادلةهوفر كيو افضل فى العيون ذات الطول المحور القصير عنه عن الاعين ذات الطول المحورى الطويل. 